Revista Universo Contábil, ISSN 1809-3337

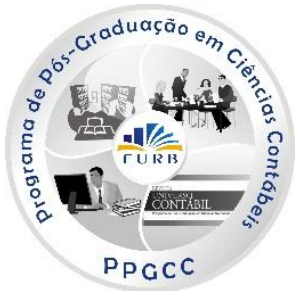

UMA ANÁLISE DO MODELO DISCURSIVO DE INSTITUCIONALIZAÇÃO APLICADO AO PROCESSO DE MUDANÇA EM CONTABILIDADE GERENCIAL ${ }^{1}$

\title{
DISCOURSE MODEL OF INSTITUTIONALIZATION APPLIED TO THE PROCESS OF CHANGE IN MANAGEMENT ACCOUNTING
}

\author{
UN MODELO DE ANÁLISIS DEL DISCURSO APLICADO AL PROCESO DE \\ INSTITUCIONALIZACIÓN DEL CAMBIO EN LA CONTABILIDAD DE GESTIÓN
}

\author{
Luciano Gomes dos Reis \\ Doutor em Controladoria e Contabilidade pela FEA/USP \\ Professor Adjunto da Universidade Estadual de Londrina - UEL \\ Endereço: Rua Antonio Pisicchio, 300 - Gleba Palhano \\ CEP: 86050-482 - Londrina - PR \\ E-mail: professorlucianoreis@gmail.com \\ Telefone (43) 9915-5898 \\ Carlos Alberto Pereira \\ Doutor em Controladoria e Contabilidade pela FEA/USP \\ Professor Assistente Doutor da FEA/USP \\ Endereço: Avenida Professor Luciano Gualberto, 908 \\ Bloco FEA 3 - Sala 230 - Cidade Universitária \\ CEP: 05508-900 - São Paulo - SP \\ E-mail: cap@usp.br \\ Telefone: (11) 3091-5820
}

\section{RESUMO}

O presente artigo tem por objetivo analisar o modelo discursivo de institucionalização, verificando as suas relações com o processo de mudança na área de Contabilidade Gerencial, por intermédio das relações existentes o estágio de codificação e institucionalização. Considerando-se a Contabilidade Gerencial como uma função administrativa presente nas organizações, a existência de um processo de mudança nesta área pode promover uma ruptura institucional, haja vista o seu possível impacto nas estruturas de poder e influência organizacional. A metodologia de pesquisa utilizada teve natureza exploratória, com caráter descritivo e ênfase no processo dialético. A existência de discursos implícitos ou explícitos em relatórios gerenciais ou demonstrações de natureza econômico-financeira pode afetar o modo pelo qual as realidades são construídas pelos indivíduos, sendo que a existência de

\footnotetext{
1 Artigo recebido em 04.04.2013. Revisado por pares em 30.09.2013. Reformulado em 14.02.2014. Recomendado para publicação em 27.03.2014 por Carlos Eduardo Facin Lavarda. Publicado em 31.03.2014. Organização responsável pelo periódico: FURB.
} 
diferentes discursos em uma organização pode afetar a institucionalização de novas rotinas, uma vez que, segundo a proposta apresentada, à medida que os discursos apresentem coerência interna e sejam bem estruturados, haverá uma tendência de existirem mecanismos auto-reguladores, que reforçarão as normas de forma consistente. Com base nessa análise, pode-se considerar que há influência do discurso no processo de mudança, dependendo da forma pela qual os conceitos que estão inseridos nos discursos de processos de mudança em Contabilidade Gerencial serão transformados em textos, utilizados na formação de regras, rotinas e hábitos, proporcionando a sua institucionalização (ou não).

Palavras-chave: Teoria Institucional. Modelo Discursivo de Institucionalização. Contabilidade Gerencial.

\section{ABSTRACT}

This article aims to analyze the discursive model of institutionalization, checking their relationships with the process of change in the area of Managerial Accounting, through the relationships the encoding stage and institutionalization. Considering the Management Accounting as an administrative function present in organizations, the existence of a process of change in this area may promote institutional breakdown, given its possible impact on power structures and organizational influence. The existence of implicit or explicit discourses in management reports or statements of economic-financial nature can affect the way in which realities are constructed by individuals, and the existence of different discourses in an organization can affect the institutionalization of new routines, since that according to the proposal, as the speeches have internal consistency and are well structured, there will be a tendency to self-regulating mechanisms that reinforce the standards consistently. Based on this analysis, we can consider that there is influence, depending on the way the concepts that are embedded in the discourses of change processes in Managerial Accounting will be transformed into texts, used in the formation of rules, routines and habits, providing your institutionalization (or not).

Keywords: Institutional Theory. Discourse Model of Institutionalization. Managerial Accounting.

\section{RESUMEN}

Este artículo tiene como objetivo analizar el modelo discursivo de la institucionalización, revisando sus relaciones con el proceso de cambio en el ámbito de la Contabilidad de Gestión, a través de las relaciones de la etapa de codificación e institucionalización. Teniendo en cuenta la Contabilidad de Gestión como un regalo de la función administrativa en las organizaciones, la existencia de un proceso de cambio en esta área pueden promover quiebre institucional, teniendo en cuenta su posible impacto en las estructuras de poder y la influencia de la organización. La metodología de investigación utilizada fue un énfasis exploratorio, descriptivo y con el proceso dialéctico. La existencia de los discursos implícitos o explícitos en los informes de gestión o declaraciones de carácter económico-financiero puede afectar la manera en que las realidades son construidos por las personas, y la existencia de distintos discursos de una organización pueden afectar la institucionalización de nuevas rutinas, ya que que de acuerdo con la propuesta, ya que los discursos tienen consistencia interna y se estructuran bien, habrá una tendencia a la auto-regulación de los mecanismos que refuerzan las normas de forma coherente. Sobre la base de este análisis, se puede considerar que existe influencia, dependiendo de la forma en que los conceptos que se incrustan en los discursos de los procesos de cambio en Contabilidad Gerencial se 
transformará en textos, que se utiliza en la formación de normas, rutinas y hábitos, siempre que su institucionalización (o no).

Palabras clave: Teoría Institucional. Discurso del modelo de institucionalización. Contabilidad de Gestión.

\section{INTRODUÇÃO}

No contexto organizacional, em que a Teoria Institucional, baseada nos conceitos da Velha Economia Institucional, possibilita o entendimento de como as decisões empresariais podem afetar e são afetadas pelos indivíduos, principalmente no ambiente interno, surgiram estruturas conceituais que buscaram explicar como acontece o processo da mudança, sob a ótica dessa teoria.

O modelo para estudo do processo de mudança conceitual, em Contabilidade Gerencial, proposto por Burns e Scapens (2000), foi elaborado por intermédio de um processo de aperfeiçoamento das proposições de Barley e Tolbert (1997), cuja proposta foi estruturar as bases conceituais para o estudo das ações no processo de formação de instituições. Os fundamentos para a análise do fenômeno de interação entre ações e instituições podem ser encontrados nos estudos sociológicos de Giddens (1978), cuja base teórica forneceu elementos para o avanço dos estudos sobre processos de mudança em Contabilidade Gerencial.

Tomando-se por base a estruturação teórica proposta por Giddens (1978), considera-se que as organizações formam estruturas e os processos de estruturação envolvem uma interação de três fatores para ligar a capacidade de conhecimento dos atores humanos às propriedades estruturais das instituições: os significados, as normas e o poder. Para Giddens:

Estes três conceitos são, analiticamente, equivalentes como termos "primitivos" da ciência social, e estão implícitos logicamente tanto na noção de ação intencional como na de estrutura: toda ordem cognitiva e moral é, ao mesmo tempo, um sistema de poder, envolvendo um horizonte de legitimação. (GIDDENS, 1978, p. 170).

Dessa forma, as organizações são formadas por meio das ações dos atores envolvidos em processos internos, que se ligam às estruturas organizacionais mediante o significado que dão a elas, às normas existentes e ao poder exercido em seu interior. Essas ações estão presentes e, muitas vezes, são externalizadas por intermédio do discurso organizacional, que constitui-se em um aspecto amplo da vida empresarial, estando presente de forma implícita ou explícita no quotidiano dos agentes presentes nas organizações.

Quando da existência de processos de mudança, especificamente na área de Contabilidade Gerencial, de acordo com os estudos de Burns e Scapens (2000), ocorre o surgimento de resistências no interior da organização, que podem minar os esforços para a implementação de mudanças. Essas forças, muitas vezes, estão inseridas em discursos organizacionais contrários ao processo de mudança. Dessa forma, apresenta-se o seguinte problema de pesquisa: é possível analisar, sob a ótica teórica, o modelo discursivo de institucionalização, proposto por Philips et al (2004), em sinergia com a proposta de Burns e Scapens (2000), para avaliar o impacto do discurso no processo de mudança em Contabilidade Gerencial?

Com base nestes pressupostos, o objetivo do presente artigo é realizar uma análise teórica sobre o modelo discursivo de institucionalização, proposto por Philips et al (2004). De forma complementar, serão verificadas as relações existentes entre o processo de mudança na área de Contabilidade Gerencial e o discurso organizacional, por intermédio da análise dos 
estágios de codificação e institucionalização, presentes no arcabouço teórico de Burns e Scapens (2000).

Para realização da presente pesquisa, optou-se pela utilização da metodologia de pesquisa com natureza exploratória, entendendo-se como aquela na qual são realizadas descrições precisas de uma situação, e onde se busca descobrir as relações existentes entre seus elementos componentes (Cervo, Bervian e Da Silva, 2007). Neste estudo, buscou-se descobrir as relações existentes entre a Teoria Institucional e o discurso organizacional. De forma complementar, pode ser classificada como de caráter descritivo e com ênfase no processo dialético, que segundo Michel (2009), consiste na busca da verdade, mesmo que provisória e reformável, por intermédio da argumentação dialogada.

\section{A CONTABILIDADE GERENCIAL E OS PROCESSOS DE INSTITUCIONALIZAÇÃO}

Segundo Reis (2008), o conteúdo simbólico dos relatórios contábeis emitidos pela Contabilidade Gerencial pode afetar as estruturas de poder internamente, independentemente da racionalidade dos agentes, mas levando em consideração a interpretação que cada gestor pode fazer, durante o processo de elaboração e leitura dos relatórios gerenciais. Os valores que proporcionam essas interpretações, segundo a Teoria Institucional, devem estar alinhados mediante a transformação dos hábitos em rotinas, buscando-se uma uniformidade nos procedimentos internos da organização.

De acordo com Oliver (1997), quando é realizada a análise das organizações sob a ótica institucional, elas funcionam dentro de uma estrutura social de normas, valores e pressuposições assumidas (taken-for-granted) a respeito do que constitui o comportamento econômico apropriado ou aceitável. Diferentemente da visão da teoria econômica neoclássica, que está baseada na premissa da racionalidade e do equilíbrio, quando da análise do processo de mudança em Sistemas de Contabilidade Gerencial sob a ótica institucional, devese considerar que os motivos do comportamento humano se estendem para além da otimização econômica, à justificação e obrigação social.

O trabalho de Barley e Tolbert (1997, p. 93-94), realizado na mesma época, apresentou uma contribuição teórica mais completa que a de Oliver (1997), pois desenvolveu uma estrutura conceitual genérica que assume que as organizações e os indivíduos que as integram estão inseridos em uma "teia" de valores, normas, regras, crenças e pressuposições assumidas, que são originadas, mesmo que parcialmente, do seu próprio interior. O objetivo da estrutura teórica, por sua vez, é investigar como as instituições afetam e como são afetadas pelas ações dos indivíduos.

Assumindo-se essa condição inicial de mutualismo entre indivíduos e organizações, em que o sistema como um todo se baseia na entidade mútua, na contribuição de todos para benefício individual de cada um, as ações sociais podem variar em seus detalhes. Entretanto, para se tornarem conhecidas de todos os atores envolvidos, elas tem que estar de acordo com as pressuposições assumidas. As especificidades da instituição são consideradas arbitrárias quando abordadas no sentido que são essencialmente estipulações sociais. A aderência a tais estipulações, entretanto, é longe de ser considerada arbitrária, se por arbitrária entender-se inteiramente aberta à escolha individual, pois os indivíduos são conduzidos a realizar determinadas escolhas. (BARLEY; TOLBERT, 1997, p. 97).

Quando da adoção de um processo de mudança, as atividades passam a ser desenvolvidas de forma contínua, adquirindo uma conotação de hábitos na esfera individual, sendo posteriormente incorporadas a um determinado grupo, passando a serem consideradas rotinas. A partir do momento em que não haja mais questionamentos sobre a sua validade podem ser considerados institucionalizados. 
O trabalho de Burns e Scapens (2000) buscou proporcionar uma estrutura institucional para estabelecer os conceitos e estágios do processo de mudança em Contabilidade Gerencial. Baseados nos conceitos de hábitos e rotinas, os autores consideram que ambos estão interconectados, proporcionando ao final de um determinado período de tempo o que se considera uma instituição. Corroborando essa visão, Busco et al. (2007, p. 34) afirmam que os sistemas de Contabilidade Gerencial são compostos de um conjunto de regras, por intermédio da formalização de procedimentos. Baseado nos conceitos de hábitos e rotinas, assim como seguindo uma seqüência na adoção de novos procedimentos, foi elaborado por Burns e Scapens (2000) um modelo que procurou sistematizar a forma pela qual as regras e rotinas agem no campo institucional ao longo do tempo. Esse modelo teórico está representado na Figura 1.

Figura 1 - O processo de institucionalização

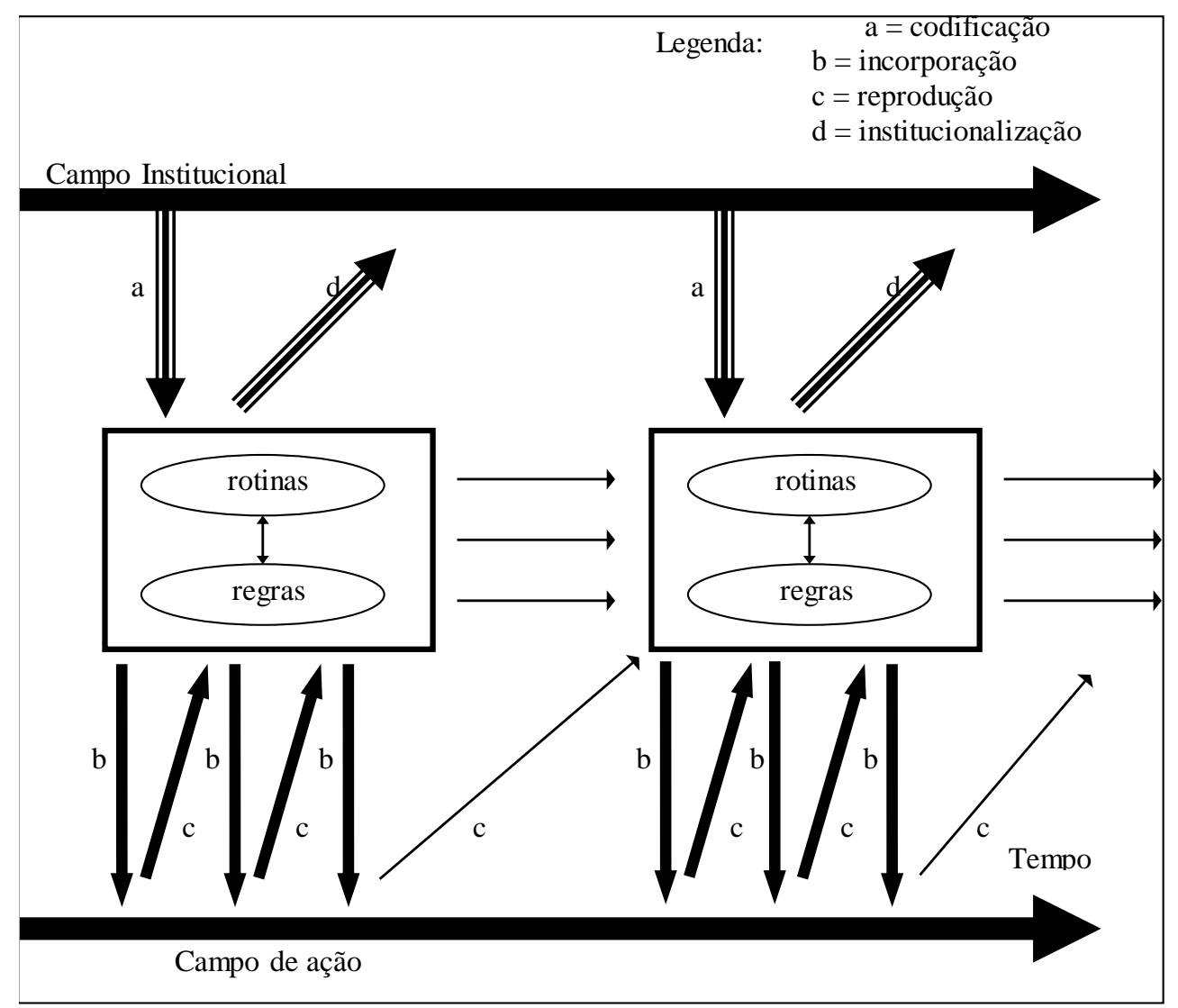

Fonte: Burns e Scapens, 2000, p. 9

O modelo de arcabouço teórico institucional que foi apresentado por Burns e Scapens (2000) permite acompanhar o processo de mudança em Sistemas de Contabilidade Gerencial. Nessa proposição teórica, consideram-se regras as instruções sobre procedimentos devidamente formalizadas e rotinas aqueles procedimentos habitualmente em uso.

A mudança dos processos no campo institucional ocorre sobre períodos de tempo mais longos do que no campo da ação. O alto da figura representa o campo institucional, visto que a parte inferior representa o campo da ação. Ambos os campos acontecem de forma cumulativa durante o processo de mudança, conforme a evolução da linha do tempo, como representado pelas linhas contínuas no alto e na parte inferior da figura. A parte central da figura ilustra a maneira conforme as regras e rotinas agem como modalidades de ligações 
entre o campo institucional e o campo da ação. As regras e as rotinas estão, também, em um processo cumulativo de mudança.

Para Burns e Scapens (2000), o processo de institucionalização ao longo do tempo, considerando-se a ação dos agentes envolvidos e fundamentado no trabalho de Giddens (1978), proporciona uma visão fragmentada do processo de institucionalização, dividida em quatro estágios distintos:

a) Encoding (Codificação);

b) Enacting (Incorporação);

c) Reproduction (Reprodução);

d) Institucionalisation (Institucionalização).

Uma vez que determinado processo de mudança foi devidamente institucionalizado, ele pode ser considerado como concluído, estando consistentemente integrado no campo de ação e no campo institucional, ao longo do tempo. Nesse momento, de acordo com os pressupostos da Teoria Institucional, abordados quando da análise da estabilidade e da mudança em Contabilidade Gerencial, qualquer ação que vise a alterar o padrão estabelecido terá resistências, uma vez que essas regras e rotinas estão "enraizadas" no comportamento individual de tal forma que seria necessário retornar ao processo de codificação, indicado pela seta (a), e passar por todas as demais fases, para que essa nova mudança alcançasse sucesso.

Barley e Tolbert (1997) consideram que as instituições são codificadas em comportamentos que representam atividades e padrões, que acontecem de forma contínua. A partir da observação da regularidade comportamental e do estabelecimento de relações entre as características das normas escritas e os comportamentos que se deseja institucionalizar, pode-se considerar que as instituições estão presentes no campo de ação. As ações podem replicar ou revisar essas regularidades comportamentais. No momento em que esses comportamentos forem considerados como independentes de situações particulares, sendo considerados como pressuposições assumidas, pode-se afirmar que as novas regras e rotinas, inicialmente codificadas, se encontram devidamente institucionalizadas.

Quando da análise do processo de mudança em organizações, Barley e Tolbert (1997) abordam que a mudança institucional pode acontecer por desejo de alterações em determinados comportamentos, cuja intenção é a busca de uma nova regularidade. Dessa forma, as mudanças provocadas mediante a adoção de novas regras, que resultarão em hábitos e rotinas, têm o objetivo de provocar alterações nas instituições já estabelecidas. O es tágio da codificação, dessa forma, possui primordial importância nas ações as quais desejam ser institucionalizadas futuramente.

A Contabilidade Gerencial pode ser considerada como um quadro composto por regras, que por meio de proposições práticas busca estruturar uma situação de ajuste organizacional, sendo armazenado mediante a codificação de conhecimentos dos indivíduos que fazem parte da organização e que possuem poder para a elaboração dessas regras. (BUSCO, 2007, p. 21). Por intermédio do sistema gerencial ocorre a formação de instituições compartilhadas, que são transformadas pelos indivíduos por meio da atribuição de significados, que se estruturam para formar as instituições a serem compartilhadas pelos demais membros.

Ocorre, então, uma espécie de permissão para que os indivíduos que detêm o poder de regulação ou normatização determinem os comportamentos que devem ser recompensados ou punidos, comunicando aos demais indivíduos da organização uma estrutura comum dos propósitos institucionais que, assim, serão compreendidos pelos demais, atingindo um nível de significação, utilizando-se para isso de elementos cognitivos presentes no processo de mudança, que podem ser compreendidas como as constatações, percepções ou ações que proporcionam aos atores a passagem das representações simbólicas à experiência. (YAZDIFAR, 2003). 
Para que o estágio de codificação possa ser considerado como iniciado, deve-se verificar se a organização possuía as regras a respeito dos procedimentos a serem seguidos durante o processo de mudança. Essas novas regras devem ser elaboradas sob a forma de normas, visando a estabelecer padrões de conduta e procedimentos a serem adotados pelos usuários da Contabilidade Gerencial, conforme preceitua o modelo de Burns e Scapens. (2000).

Como componente do estágio de codificação, também é desejável a existência de um planejamento pela equipe responsável, que estipule prazos, recursos financeiros e demais recursos físicos e humanos necessários à implementação do processo de mudança. Para isso, os responsáveis pela elaboração das regras devem ter pleno conhecimento das operações da organização, bem como devem alinhar os resultados esperados com a missão, os valores e a finalidade da organização.

Para a definição do momento em que o processo de mudança está concluído, bem como se os conceitos de Contabilidade Gerencial implementados se encontram devidamente institucionalizados, realizando-se uma análise sobre a eficácia do processo de mudança, necessita-se de uma observação criteriosa de seus usuários, assim como é importante a visão da Alta Administração a respeito do processo.

Nesse estágio, é importante observar se ocorre o emprego dos novos relatórios e dos indicadores de forma adequada ao processo de gestão, havendo uma ligação clara entre o processo de tomada de decisão e as informações fornecidas pela Contabilidade Gerencial. Isso é necessário para verificar a existência de hábitos pessoais, rotinas e regras organizacionais de acordo com os conceitos introduzidos pelo processo de mudança, havendo a aceitação das novas normas como pressuposições assumidas (taken-for-granted) sem questionamentos. A partir desse momento, pode-se afirmar que o campo institucional está devidamente materializado no campo de ação da organização, mediante as regras e rotinas previstas nos manuais, conforme demonstram os trabalhos de Soin et al. (2002), Siti-Nabiha e Scapens (2005) e Vieira e Hoskin (2005).

Considera-se que, uma vez atendidos esses requisitos, a organização obteve eficácia no seu processo de mudança em Contabilidade Gerencial, podendo constatar-se, entretanto, indícios de resistências ou barreiras. Nesse estágio, os atores envolvidos utilizam, individualmente e em grupo, os conceitos novos de forma cotidiana, fazendo uso efetivo das informações geradas, dos relatórios e dos indicadores baseados nos conceitos que a organização desejava estarem institucionalizados em seu processo de gestão e de tomada de decisão.

\section{CODIFICAÇÃO, A PRESENÇA DO DISCURSO E A FORMAÇÃO DE INSTITUIÇÕES}

Na visão de Phillips et al. (2004), em um processo de institucionalização de novas regras, o discurso assume um papel importante na formação de instituições, pois as ações organizacionais produzem textos e esses textos contêm um discurso e esse discurso influencia de forma preponderante a formação de instituições, ou seja, a institucionalização. A produção de textos ou a codificação, conforme especificado no modelo de Burns e Scapens (2000), contém, em seu interior, um discurso, que exercerá influência na forma pela qual serão produzidas instituições, ao final de um determinado período de tempo.

Durante o quotidiano organizacional, cada indivíduo tem que, constantemente, dar significado a uma série de eventos, encontros e atividades das quais ele participa ativamente. (WEICK, 1973). O significado das ações dos indivíduos e daqueles que o cercam é considerado como uma interpretação da realidade, não algo simplesmente dado como verdadeiro. A atribuição de significados aos fatos que acontecem sempre possuem uma característica subjetiva, que tem, inserida em seu interior, riscos a respeito da interpretação de 
determinados textos realizada individualmente. Segundo Phillips e Hardy (2002, p. 5), essa formação de significados não acontece de forma isolada, mas é formada por um conjunto de textos que vão sendo produzidos no decorrer do tempo e que, inter-relacionados, possibilitam a formação de conexões entre textos, discursos e realidade social, que podem ajudar ou dificultar a formação de instituições no interior das organizações.

Para Dambrim et al. (2007, p. 178), quando os chamados "ideais" organizacionais são transformados em sistemas, que possuem relações e modelos causais, acontece a formação de um discurso, no sentido de algo que seja definido e proposto como uma ação no campo real. Nesse contexto, há muitas definições a respeito do que é o discurso. O discurso está inserido nas práticas diárias, produzindo a realidade e sendo produzido por ela, por meio das diversas interações sociais que ocorrem de forma quotidiana entre os indivíduos. (PHILLIPS; HARDY, 2002, p. 3). Por meio do discurso, presente no sistema social, é que será possível a elaboração de técnicas e medidas de desempenho, que terão sua utilidade direcionada para o controle dos resultados esperados de determinada ação. Esse processo de inserção de novas técnicas, como as rotinas de Contabilidade Gerencial, devem ser internalizadas pelos indivíduos, provocando, assim, a institucionalização de novos procedimentos. Esse processo de representação pode ser analisado pela Figura 2.

Figura 2 - Estágios de institucionalização pelo discurso

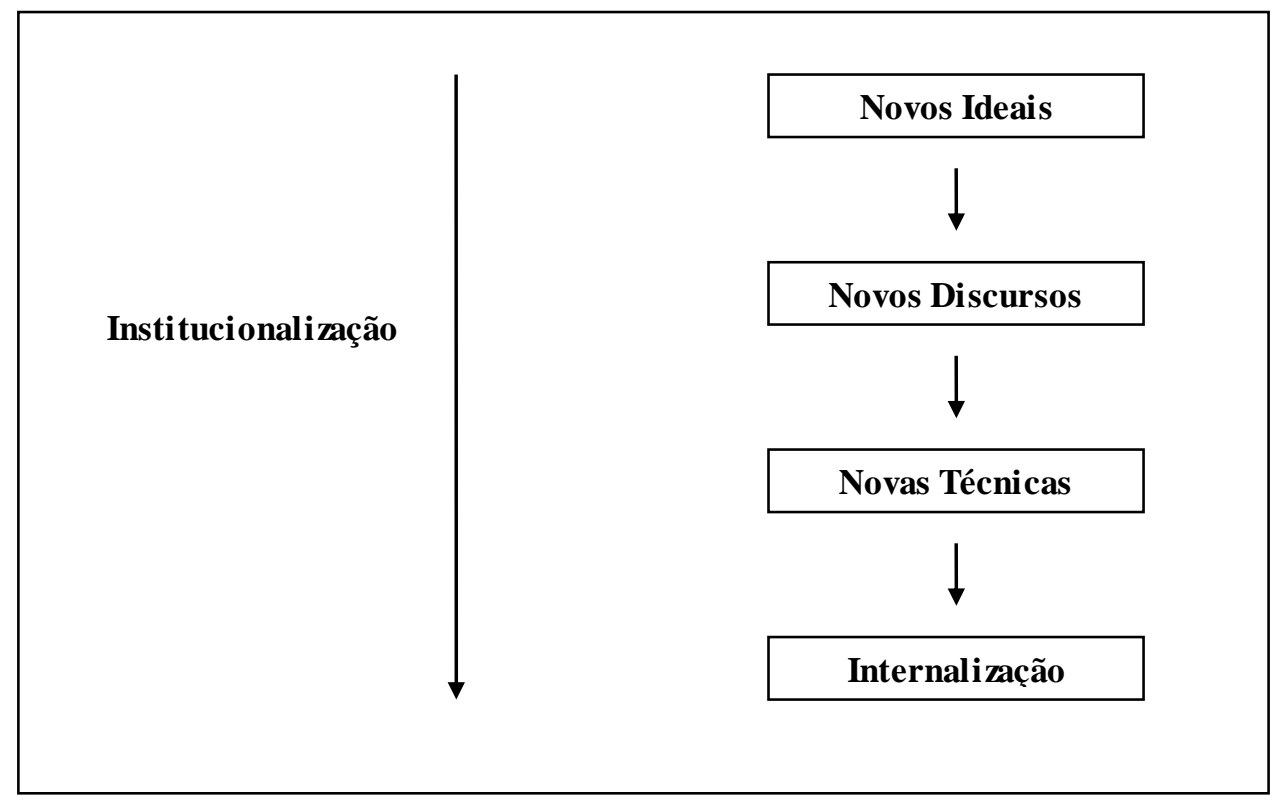

Fonte: Dambrim et al., 2007

De acordo com Mumby (1988, p. 158-159), o processo de linguagem no interior das organizações está ligado diretamente à interpretação dos atos administrativos por parte dos tomadores de decisão. Em sua argumentação, esse autor considera que as funções exercidas pelo discurso constituem uma estrutura conceitual teórica que facilitam o entendimento e a interpretação dos eventos inerentes ao processo de tomada de decisão. Isso pode ocorrer nos processos de negociações políticas que interfiram nas relações de poder, podendo ou não criar resistência por parte dos demais indivíduos que interagem, cotidianamente, com uma determinada estrutura organizacional.

Para esses objetivos, o processo de escrita é considerado um modo de produção textual-discursivo, com fins comunicativos e certas especificidades materiais e se caracteriza por sua constituição gráfica, embora possa envolver, também, recursos, como, por exemplo, de ordem pictórica. (MARCUSCH, 2001). Os documentos, formalizados por meio de uma 
forma escrita, podem ser considerados autônomos, uma vez que possuem significados neles mesmos; explícitos e condensados, pois fornecem de forma clara o resumo de intenções provenientes de discussões verbais e reuniões anteriormente realizadas e, por final, são documentos planejados e normatizados, que têm por objetivo se transformarem em rotinas no cotidiano organizacional, sujeitas à interpretação individual de cada um dos atores sociais que os utilizem.

Esse ato interpretativo encontra-se fundamentado em dimensões pessoais de linguagem, constituídas de imagens e, eventualmente, de metáforas que são familiares ao indivíduo, utilizadas para interpretar determinados eventos, internalizar as relações de poder existentes e acondicionar as normas estabelecidas dentro de determinado padrão de moralidade, das leis e dos costumes que devem ser respeitados. (BOLAND JR., 1993, p. 125).

De acordo com Boland Jr. (1993, p. 126), pode-se considerar que as pessoas envolvidas com o processo contábil participam do ato de interpretação de textos organizacionais ora como leitores, ora como elaboradores desses textos, que podem estar em forma de relatórios, registros, manuais de contabilidade, entre outros. Esses textos produzidos, por sua vez, quando de posse dos efetivos usuários da informação contábil, são por eles interpretados e utilizados no processo de tomada de decisão.

Essas ações individuais provenientes da utilização das informações fornecidas pelos sistemas contábeis aos indivíduos conduzem a uma habitualização de rotinas, mediante a reprodução de comportamentos, que devem culminar com a institucionalização de determinados conceitos, conforme especifica o modelo de Burns e Scapens (2000).

Tomando-se como parte inicial de um processo de institucionalização de rotinas contábeis, o estágio de codificação, de acordo com as abordagens teóricas propostas por Barley e Tolbert (1997) e Burns e Scapens (2000), parte-se do pressuposto de que esse estágio está estruturado mediante o estabelecimento de esquemas escritos. Esses esquemas são provenientes da materialização de atos interpretativos de indivíduos que fazem parte da organização, bem como pode existir a contribuição de consultores externos, que auxiliam no processo de mudança de conceitos na Contabilidade Gerencial, que devem estar devidamente codificados, constituindo a representação do conhecimento prático acumulado em um conjunto de normas adaptadas para um determinado cenário. Como representam uma nova situação organizacional, essas novas normas influenciarão a forma como os indivíduos se comunicarão no interior da organização, determinando quais comportamentos devem ser recompensados e quais devem ser punidos, buscando-se a padronização e institucionalização de processos no interior da organização.

Segundo Barley e Tolbert (1997, p. 110), constituem elementos desse processo de codificação diversos tipos de documentos, tais como: manuais de treinamento, registros legais, memorandos, jornais internos e todos os conteúdos que constituem instrumentos de comunicação ou divulgação interna de informação. As mudanças em parâmetros institucionais podem ser obtidas mediante uma análise detalhada dos processos devidamente codificados, que representam a implementação de novos conceitos na Contabilidade Gerencial, alterando a forma pela qual o processo de tomada de decisão é estruturado, estabelecendo os limites da mudança desejada. Faz parte da codificação, de forma suplementar, a estrutura básica de conceitos que nortearão a mudança durante todo seu processo, estabelecendo-se um modelo de Controladoria específico. Esses dados podem fornecer ainda uma descrição do tipo de eventos que provocaram o início do processo de mudança, bem como podem fornecer suporte para as conclusões a respeito da eficácia do processo, mediante a comparação entre as rotinas observadas em efetivo funcionamento e aquelas que, embora previstas no projeto inicial de mudança, não se encontram ainda institucionalizadas.

A análise do processo de codificação, em um processo de mudança em Contabilidade Gerencial, pode ser realizada mediante a análise do discurso. Para Alvesson e Karreman 
(2000, p. 1126), há dois tipos principais de abordagens que podem ser realizadas, quando da utilização dessa técnica em estudos em organizações. A primeira é relativa ao estudo do texto social, considerando a linguagem falada e o texto escrito em seus contextos sociais da ação. A segunda abordagem é aquela na qual o estudo da realidade social é tido como construído, visando a dar forma à realidade social por meio da linguagem. A primeira forma de tratar o discurso destaca o "texto falado" e a natureza textual das interações diárias na organização. A segunda forma, que é utilizada no presente trabalho, busca a determinação de uma dada realidade social, mediante a análise dos movimentos historicamente determinados. Não se pode excluir, contudo, uma definição a respeito da disciplina como um princípio presente na produção do discurso. De acordo com Foucault (2006, p. 36), a disciplina está sempre presente na elaboração de discursos, fixando os limites e atribuindo uma identidade que forma o corpo do discurso, permitindo uma "reatualização" permanente das regras existentes.

Nesse contexto específico, torna-se necessária uma conceituação clara do discurso a ser utilizado. O discurso, quando considerado um campo de estudo, é bastante amplo, incluindo desde as declarações fornecidas por assessores de imprensa até notícias sobre determinado assunto publicadas nos meios de comunicação de massa, que influenciam o comportamento das organizações. A análise do discurso pode ser objeto de pesquisa de diversas disciplinas, entre elas o estudo da linguagem, a semiótica e a psicologia. Com a finalidade de delimitar o campo de estudos, utilizou-se a definição de discurso proposta por Fairclough (1992) e Parker (1992), que definem discurso como conjunto de declarações que estão presentes em textos e manuais de procedimentos, trazendo em seu interior um objeto de ação dos indivíduos. Dessa forma, constitui-se como objeto de análise deste trabalho o discurso formal emitido pela organização, como um meio de inserir uma prática operacional por intermédio de determinado processo de comunicação, proporcionando uma ação de interação entre os indivíduos em determinados cenários organizacionais e institucionais específicos.

De forma complementar a essa abordagem, considera-se que o discurso é algo mais completo, não apenas descrevendo determinadas coisas ou fatos, mas estando presente um processo de construção da realidade, por meio da argumentação e subjetivação que permite a interpretação da linguagem por uma diversidade de indivíduos. (ORLANDI, 1999, p.21).

Deve haver uma distinção entre o discurso e os outros elementos que possam estar presentes na comunicação. Van Dijk (1993, p. 251) apresenta argumentos que visam a estabelecer condições para que possa haver um exame detalhado do papel desempenhado pelas representações sociais nas mentes dos atores sociais. Para que se possa trabalhar, adequadamente, a análise do discurso, deve haver uma multidisciplinariedade nas metodologias de estudo. Embora não caracterizando o objetivo principal deste trabalho de pesquisa, assuntos como aspectos cognitivos sociais, estruturas de poder e características culturais no interior das organizações constituem temas que podem ser examinados, permitindo uma visualização completa das interações sociais provenientes do discurso.

Para Lefèvre e Lefêvre (2003, p. 14-15), quando da realização de uma pesquisa de natureza social, deve-se considerar o uso da análise de discurso como recurso para identificação do pensamento coletivo, não se utilizando, apenas, de questões fechadas que serão tabuladas, mas também de técnicas que possam auxiliar na identificação de categorias de idéias que estão expressas no discurso. Atente-se ao fato de que, na execução do presente trabalho, se utilizou da versão do chamado microdiscurso (ALVESSON; KARREMAN, 2000, p. 1133), em que os textos sociais são analisados em um microcontexto específico, ou seja, somente os textos relativos à Contabilidade Gerencial. As outras três versões de análise de discurso (abordagens de meso-discurso, discurso-principal e megadiscurso) visam a realizar estudos mais amplos, como, por exemplo, generalizações em contextos locais, características culturais de um grupo de organizações ou, ainda, discurso sobre temas 
considerados universais, como, por exemplo, globalização e reengenharia, que são explorados por estudos relacionados à Nova Sociologia Institucional.

Uma avaliação de como um discurso externo à instituição pode influenciar a competitividade de uma instituição financeira, como no estudo realizado por Langenohl (2008), fornece informações valiosas sobre o ambiente externo e as forças institucionais que provocam pressão sobre a organização. Entretanto, ele não aborda o discurso interno, que, por sua vez, pode exercer influência na forma pela qual os conceitos gerenciais são implementados, incorporados e institucionalizados.

A utilização da análise sobre o microdiscurso dá-se em razão de a Contabilidade Gerencial constituir-se em uma micro-perspectiva, na qual são verificadas as práticas gerenciais dentro das organizações, em que são observados processos de adoção e resistência à implementação de conceitos inovadores em um local com papel específico dentro da empresa. (RIBEIRO; SCAPENS, 2006, p. 95).

Considerando esses pressupostos, não se pode considerar o discurso como um elemento simples da comunicação. Além dos elementos básicos existentes em um sistema de comunicação (emissor, receptor, código, referente e mensagem), que remete a uma idéia de transmissão de uma determinada informação, avalia-se o discurso como algo mais completo, no qual está inserido um processo de argumentação, subjetivação e construção da realidade. (ORLANDI, 1999, p. 21).

Para Phillips e Hardy (2002, p. 63), os estudos que tenham por abrangência o discurso devem explorar a produção discursiva dos aspectos da realidade social. Verifica-se que a narrativa, em forma de discurso, tem suas origens em processos racionalistas, buscando formar instituições como meio de transformar hábitos em rotinas na forma de pressuposições assumidas. Entretanto, no processo de elaboração do discurso pelos indivíduos, revela-se um grau de subjetividade subjacente, no qual estão inseridos os desejos e os anseios de poder daqueles que o elaboram, conforme descrito por Foucalt (2004, p. 9-10). Assim sendo, considera-se que, em um sentido amplo, o discurso pode ser considerado como a prática da escrita (por meio de textos) e da fala. (WOODILLA, 1998). Um conceito dessa amplitude, entretanto, não possibilita um processo de análise específico. Para Parker (1992. p. 5), o discurso é considerado um sistema das indicações que constroem objetos.

$\mathrm{O}$ discurso presente nas regras, que se transformam em normas com vistas a implementar rotinas, tende a se transformar em atos reais no campo de ação, saindo do campo institucional e transformando-se em algo que faça sentido para os atores envolvidos em determinado processo social, como nas organizações, incluindo os processos de Contabilidade Gerencial. A forma pela qual o discurso contido nos textos exerce uma influência na formação de instituições pode ser visualizada no modelo proposto por Philips et al (2004), detalhado na seção a seguir.

\section{O MODELO DISCURSIVO DE INSTITUCIONALIZAÇÃO DE PHILLIPS et al. (2004)}

A utilização do discurso como elemento de análise no campo organizacional remonta ao trabalho de Berger e Luckman (1967), que apresentam propostas teóricas a respeito de como a realidade social emerge da construção mental humana. Suas origens ocorrem por meio da interação entre os diversos agentes nos processos sociais, sendo que as normas, re gras e valores construídos em um determinado grupo social são transmitidos para os outros indivíduos do mesmo grupo pelos processos de socialização.

A visão do discurso influenciando a Contabilidade e por ela sendo influenciado pode ser encontrada, por exemplo, nos estudos realizados por Burchell et al. (1980), segundo os quais a concepção de realidade individual dos atores organizacionais é regida pelo discurso organizacional dominante, sendo que a seleção de indicadores dos sistemas organizacionais 
ocorre por intermédio de um processo de negociação, promovendo uma alteração na prática contábil quotidiana. Abordando essa mesma questão, Colville (1981) recomenda que a análise do processo contábil deve considerar os aspectos do comportamento humano, pois os sistemas contábeis não existem de forma isolada no interior das organizações, mas interagem com outros sistemas e afetam a forma pela qual os indivíduos percebem a realidade.

A racionalidade econômica, sob essa perspectiva, é questionada, ao se considerar que as práticas contábeis se desenvolvem em um ambiente sob a ótica institucional, que sofre influências de aspectos culturais e comportamentais, oposta, em determinadas situações, ao determinismo econômico. (PANOZZO; ZAN, 1999, p. 51-52). Na Teoria Institucional, a formação de instituições depende das interações sociais (BERGER; LUCKMAN, 1967, DIMAGGIO; POWELL, 1983), e essas interações que visam à formação de instituições ocorrem por intermédio da produção de informações que constituem, no campo organizacional, uma complexa teia de regras institucionais, recursos e imposição de limites. (PHILLIPS et al., 2000, p. 27-28).

Segundo Miller (1994, p. 9-11), altera-se a visão, estritamente econômica, de que as informações, oriundas dos sistemas contábeis e estabelecidas em normas, regras e procedimentos, estão inseridas em um domínio estritamente técnico, impessoal. Essas informações, produzidas pela Contabilidade, estão inseridas no contexto de promover a organização como racional, responsável e moderna, fornecendo vocabulários próprios para delinear metas organizacionais, procedimentos e políticas internas.

Nesse ambiente organizacional, a produção de textos que exercerão influência na forma pela qual os gestores executarão o processo de tomada de decisão constitui um importante instrumento, para a coesão organizacional. Lammers e Barbour (2006, p. 364-365) propõem uma inter-relação entre o processo de comunicação e a formação de instituições. Para esses autores, o processo de comunicação sustenta as instituições, alinhando os objetivos organizacionais com a formação de instituições, por meio da comunicação formal.

A comunicação formal possui, incorporada no seu interior, a presença de discursos implícitos ou explícitos, que segundo Phillips e Hardy (2004, p. 4) constituem a manifestação material do discurso. Hardy et al. (2000, p. 1244-1245) consideram que a atividade discursiva, no interior das organizações, possui um alto nível de complexidade, podendo ser analisado sob diversas vertentes, inclusive como recurso estratégico das organizações, para alcançar determinados objetivos organizacionais.

Considerando-se que o discurso presente nos textos formais das organizações influencia o processo de comunicação organizacional e esse influencia a formação de instituições, Phillips et al. (2004, p. 635) apresentam a análise do discurso como uma estrutura coerente para a investigação de processos de institucionalização. Eles afirmam que uma análise da estrutura analítica do discurso pode proporcionar um melhor entendimento de como as instituições são produzidas e mantidas no decorrer do tempo.

Partindo-se das concepções de produção social de fenômenos organizacionais e interorganizacionais por meio do discurso, abordados por Alvesson e Karreman (2000), Hardy et al. (2000) e Phillips e Hardy (2002), há uma proposta de modelo de como as idéias, socialmente produzidas, são transformadas e transformam organizações, instituições e o mundo social, sendo gerados e mantidos pelas relações existentes entre discursos, textos e ações. Essa interação entre discursos, textos e ações encontra-se demonstrada na Figura 3.

O modelo de integração entre textos, discursos e ações nas organizações, elaborado por Phillips et al. (2004), propõe que há uma relação mutuamente constitutiva por intermédio da ação dos textos e dos discursos no processo de formação de instituições.

O processo de institucionalização, na visão de Phillips et al. (2004, p. 640), não acontece pela pura e simples imitação de uma ação determinada, pelos atores organizacionais. A institucionalização de determinadas regras e procedimentos ocorre pela criação de textos 
que vão apresentar, por meio de manuais, artigos, livros e outros meios textuais, descrições sociáveis no meio ambiente organizacional, constituído de indivíduos que trabalham em um mesmo setor ou se utilizam de um mesmo padrão de relatórios, para a tomada de decisão.

Figura 3 - A relação entre ação e discurso
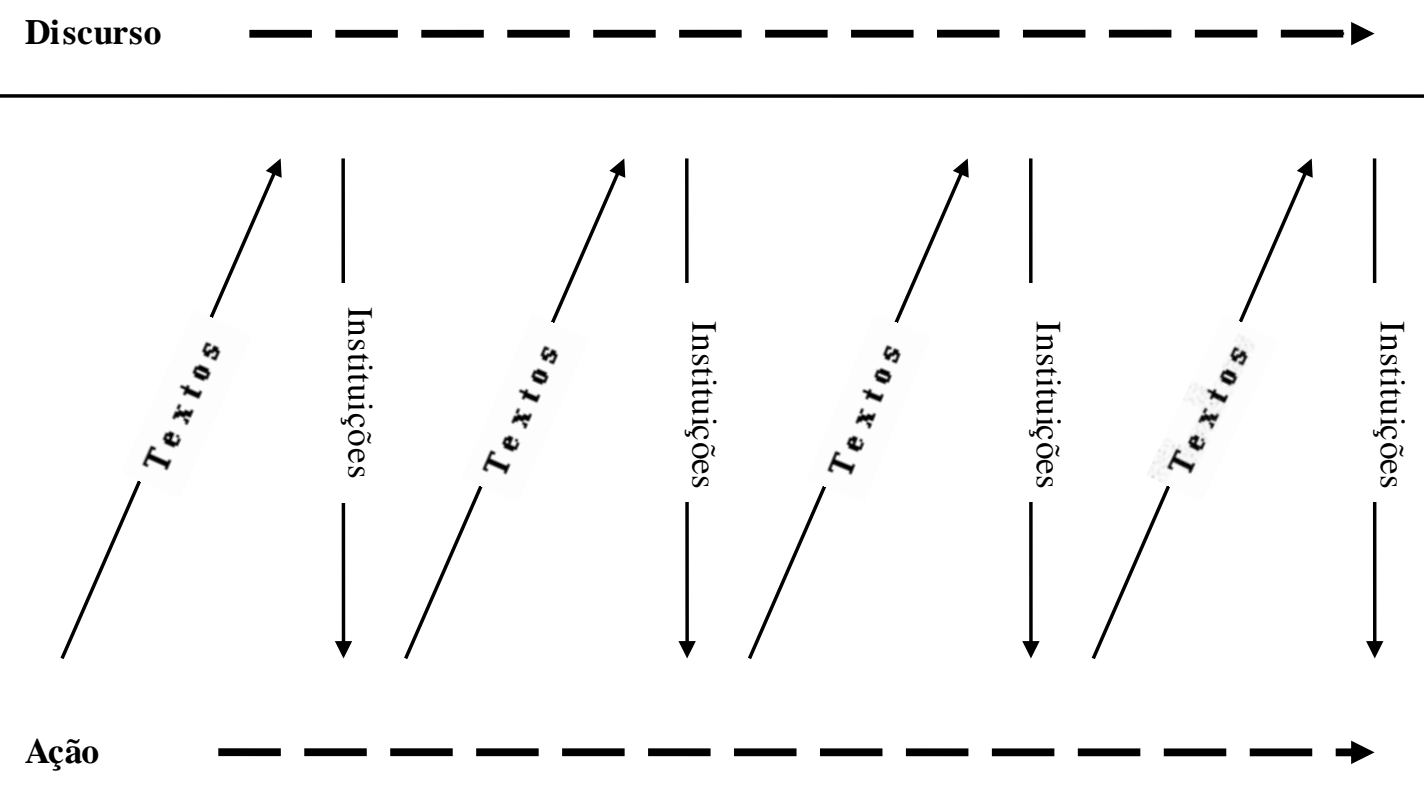

Fonte: Phillips et al., 2004, p. 639 (tradução livre)

No modelo apresentado na Figura 3, as setas para cima, em posição diagonal, demonstram como as ações de atores individuais afetam o campo discursivo pela produção de textos. De todos os textos produzidos, alguns produzirão efeitos, que serão incorporados em discursos já existentes, ou ainda, produzirão novos discursos no meio organizacional. Esses discursos irão fornecer as condições necessárias para que sejam constituídas socialmente novas instituições, que desenvolverão ações para a produção de mais textos. Assim, os atos desenvolvidos pelos indivíduos no campo discursivo influenciarão a forma pela qual as ações são realizadas, estabelecendo recompensas para algumas ações e punindo outras, como ilustrado pelas setas verticais descendentes, da Figura 3.

Tomando-se por base as questões levantadas por Phillips et al (2004, p. 640), embora várias ações no ambiente organizacional possam ser associadas com algum texto formal elaborado internamente, as representações resultantes e os efeitos de muitos desses textos será localizada, limitada e sem maiores conseqüências. Para o estudo do processo de institucionalização, fundamentada na estrutura conceitual de Burns e Scapens (2000), tomando-se por base sua fase inicial (codificação) e a sua fase final (institucionalização), a função inicial da análise do discurso é identificar as ações que resultaram em textos formais no processo de codificação. A partir dessa análise primária, parte-se para a investigação dos textos formais, visando a extrair os fundamentos que permitam identificar as ações presentes no conteúdo desses textos que se transformaram em ações efetivas, devidamente institucionalizadas.

Partindo-se do trabalho original elaborado por Phillips et al. (2004), entende-se que a produção de textos internamente pelas organizações é considerada uma fonte de procedimentos que podem ser institucionalizados, por meio da apresentação de inovações no processo organizacional que intervêm de forma proativa, proporcionando novas explicações a respeito da realidade social na qual estão inseridos. Nesse processo, a reificação, ou seja, a transformação de regras abstratas em algo concreto para os atores sociais, é desejada, no 
sentido de que, quanto maior a objetificação dessas normas na vida social dos indivíduos, maior a possibilidade de aderência aos conceitos nelas existentes.

Baseando-se nos estudos de Weick (1979) e de Berger e Luckman (1967), Phillips et al. (2004) desenvolveram, então, um modelo com fundamentação em duas das principais características das ações que produzem instituições: em primeiro lugar, as ações que são inovadoras e que, portanto, requerem significativo esforço organizacional para fazerem sentido junto aos receptores e, em segundo lugar, as ações que possam afetar a legitimidade da organização, seja ela interna ou externa.

A síntese do modelo proposto por Phillips et al. (2004), para demonstrar como o discurso está inserido no processo de institucionalização de textos, no campo organizacional, está demonstrada na Figura 4.

Figura 4 - Um modelo discursi vo de institucionalização

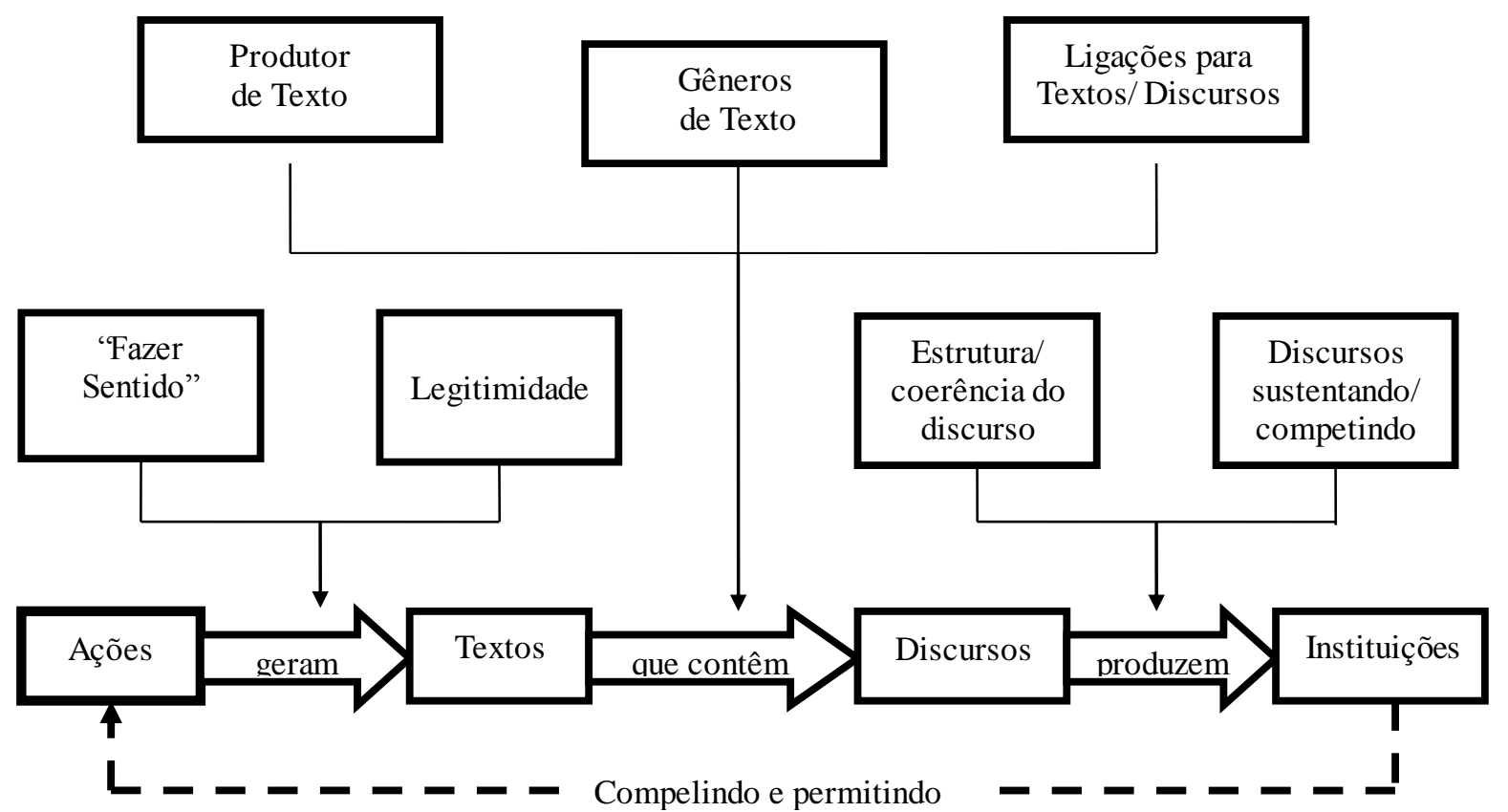

Fonte: Phillips et al., 2004, p. 641 (tradução livre)

Com base no modelo demonstrado na Figura 4, Phillips et al. (2004) fazem sete proposições teóricas, que objetivam demonstrar a importância dos textos e dos discursos no processo de institucionalização nas organizações.

A primeira e a segunda proposições, representadas pela parte superior do modelo da Figura 4, dizem respeito às ações que terão maior chance de produzir textos. Phillips et al. (2004) propõem que as ações que exigem um maior esforço organizacional, em virtude de sua característica inovadora, procurando fazer sentido para todos os atores individualmente, conforme explicitado por Weick (1979), terão mais chances de resultar em textos que serão disseminados amplamente do que as ações que não representem um aspecto inovador. A segunda proposição, por sua vez, especifica que as ações que afetam as percepções de legitimidade da organização terão maior probabilidade de resultar em textos que serão largamente utilizados, em relação àqueles que não afetarem a legitimidade organizacional. Ambas as proposições referem-se a fatos anteriores ao processo de institucionalização, estando ligadas ao processo de construção de textos que podem (ou não) ser adotados pela organização, na forma de regras e procedimentos formais.

A terceira, quarta e quinta proposições tratam da forma de produção de textos, que poderão produzir discursos, considerando as características explícitas e implícitas do processo 
de formação textual das organizações, conforme preceitua Fairclough (1992). A terceira proposição trata, especificamente, das características dos atores organizacionais que produzem textos: aqueles atores que possuírem o direito legítimo de emitir textos ou que representem uma autoridade formal, produzirão textos com conteúdos que terão maior chance de serem inseridos como parte do discurso organizacional, do que os textos emitidos por outros atores, não munidos de tal poder. A quarta proposição, no mesmo sentido, expõe o fato que textos que sejam reconhecidos, interpretados e utilizados por outras organizações (utilizando-se de técnicas de benchmarking) são mais prováveis de ficarem inseridos no discurso organizacional do que aqueles que não possuem tal atributo. A quinta proposição, de forma complementar, expõe que os textos que possuam em seu interior conceitos e constructos de discursos mais amplos, bem estabelecidos na organização, terão maior probabilidade de serem incluídos no campo organizacional, do que aqueles que representem novos discursos.

Na sequiência, Phillips et al. (2004, p. 645) estabelecem a sexta e a sétima proposições, que são:

[...] Discursos que são mais coerentes e estruturados são mais prováveis para produzir instituições do que aqueles que não são.

[...] Discursos que são suportados por discursos amplos e que não são altamente contestados por discursos competidores são mais prováveis para produzir instituições do que aqueles que não são. (PHILLIPS et al., 2004, p. 645) (tradução livre).

Por meio dessas duas proposições, representadas parcialmente pelo conteúdo situado na parte inferior direita do modelo da Figura 4, considera-se que à medida que os discursos apresentem coerência interna e sejam bem estruturados, haverá uma tendência de existência de mecanismos auto-reguladores, que reforçarão as normas de forma consistente. Da mesma forma, a existência de discursos que ofereçam construções sociais alternativas, a respeito de um mesmo aspecto da realidade social, poderá reduzir a probabilidade de um determinado discurso institucionalizar-se, em virtude da competição existente que tende a provocar contestações de várias formas pelos indivíduos.

A análise do processo de mudança conceitual em Sistemas de Contabilidade Gerencial, com a formação de instituições analisada pela Teoria Institucional, sob a ótica da Velha Economia Institucional e com a perspectiva do modelo proposto por Burns e Scapens (2000), constitui-se em um campo para a aplicação do modelo discursivo de institucionalização de Phillips et al. (2004), haja vista que o estágio de codificação constitui no momento de produção de textos que se desejam institucionalizados, podendo apresentar discursos concorrentes, que influenciarão a formação de instituições pela organização, provocando a institucionalização de ações distintas daquelas previstas inicialmente.

O estágio de codificação presente em processos de mudança de Contabilidade Gerencial e a formação do discurso dependem diretamente dos indivíduos que recepcionarão as mensagens emitidas por intermédio dos textos produzidos e que se desejam institucionalizados. Segundo McCroskey (1968, p. 34-35), a mensagem emitida com a intenção de formação e mudança de atitudes pode ser produzida pensando-se em determinados grupos, mas a internalização dessas mensagens sempre ocorrerá individualmente. A importância da percepção dos indivíduos em relação a um determinado discurso é ressaltada, uma vez que cada pessoa possui um repertório de crenças, sendo que essas crenças podem conduzir à aceitação ou a um processo de resistência a determinada mudança.

Dessa forma, considera-se que o discurso deve ser estruturado de acordo com a natureza do seu público-alvo, levando-se em consideração a mudança que se deseja alcançar 
ao final de um determinado período de tempo. Os interlocutores da organização, assim considerados os indivíduos que participarão como comunicadores do processo devem ter legitimidade perante os receptores da mensagem, constituindo-se em um meio facilitador da mudança a existência de aceitação do interlocutor como legítimo, por parte do público receptor da mensagem.

A existência de discursos implícitos ou explícitos em relatórios ou demonstrações de natureza econômico-financeira pode afetar o modo pelo qual as realidades são construídas pelos indivíduos. Na visão de Lehman (2006, p. 305-319), a Contabilidade pode apresentar diferentes discursos. De acordo com esse autor, enquanto o discurso econômico, da lucratividade expressa na "botton line" constrói o mito da racionalidade e da eficiência, podese estar obscurecendo relações complexas, o que pode provocar efeitos danosos à sociedade em geral. A forma pela qual as organizações relatam suas operações e seus resultados pode revelar as intenções da organização sobre determinados assuntos, expondo contradições ou situações específicas. Para Ezzamel et al. (2007, p. 169), discursos que contenham padrões regulatórios podem afetar os meios pelos quais os atores sociais prestam contas de suas ações, combinando novas e velhas rotinas e produzindo hábitos e rotinas diversos daqueles previstos em um padrão normativo inicial. Os discursos de natureza racional-econômica, segundo Ezzamel et al. (2007) podem entrar em conflito com fatores qualitativos de natureza social, afetando a legitimação de normas contábeis que se desejam institucionalizadas.

Para MacDonald e Richardson (2002, p. 150), a abordagem por meio de métodos e teorias não convencionais, dos processos de mudança em Contabilidade Gerencial, pode contribuir para a formação de teorias ou a realização de trabalhos empíricos, analisando-se influências e contextos que não seriam revelados mediante métodos tradicionais de pesquisa.

A percepção de que o discurso inserido nas práticas de Contabilidade Gerencial possa ser utilizado para finalidades de natureza não técnica foram objeto de estudo de autores como Hopper e Armstrong (1991, p. 437-446) e MacDonald e Richardson (2002, p. 120-156). Segundo o trabalho de Hopper e Armstrong (1991), o desenvolvimento da Contabilidade Gerencial foi acompanhado pela necessidade emergente de mecanismos de controle do processo de trabalho, realizando a separação daqueles que detêm o conhecimento daqueles que trabalham na produção.

Quando realizou uma análise das relações entre a sociedade e as instituições financeiras do Reino Unido, Coupland (2006, p. 867-868) recuperou o conceito de contrato social, no qual as organizações, embora orientadas para o lucro, firmam um acordo intangível com a sociedade. Esse acordo visa a atender os interesses de um grupo mais amplo de interessados, além dos acionistas, cujos interesses vão além das perspectivas financeiras. Para essa autora, uma observação mais atenta do setor bancário conduz para a análise de que, embora gerando riqueza de forma substancial para a sociedade, as preocupações de natureza social normalmente não fazem parte de sua rotina, embora sejam relevantes e oportunas. Caso haja, na organização, a presença de um discurso social e um discurso econômico, a produção de relatórios contábeis e o processo de decisão podem ser afetados, com a geração de tensões ou conflitos que afetam o processo de institucionalização de conceitos.

O estudo realizado por Reis (2008), em uma instituição financeira pública brasileira, demonstrou a existência do discurso social e do discurso econômico competindo em uma organização, sugerindo a existência de diferentes graus de institucionalização do processo de mudança em Contabilidade Gerencial em função dos discursos de preferência dos indivíduos. Segundo o mesmo autor, com base nas análises realizadas, nas quais foram utilizadas técnicas de natureza qualitativa e quantitativa, pode-se inferir que a existência de discursos competidores pode produzir diferentes níveis de institucionalização, que serão maiores quanto mais coerentes com o discurso organizacional, corroborando, dessa forma, a hipótese central 
de que o discurso formal influencia na institucionalização de conceitos de Contabilidade Gerencial.

\section{CONCLUSÕES SOBRE A ANÁLISE DISCURSIVA DA INSTITUCIONALIZAÇÃO DO PROCESSO DE MUDANÇA}

Concluindo as considerações sobre a utilização da análise discursiva da institucionalização do processo de mudança em Contabilidade Gerencial, deve-se ter em mente a não linearidade deste processo. Embora exista um modelo que preveja condições e uma seqüência na institucionalização de novos procedimentos em Contabilidade Gerencial, assim como um modelo discursivo de institucionalização, a prática organizacional real não está limitada a esses modelos, pois as empresas podem apresentar comportamentos de forma não sistemática ou racional, alterando a ordem proposta.

Todos esses aspectos possuem sua importância, influenciando diretamente a forma pela qual os conceitos a serem inseridos nos discursos de processos de mudança em Contabilidade Gerencial serão transformados em textos, utilizados na formação de regras, rotinas e hábitos, proporcionando a sua institucionalização (ou não). Por meio da análise de como a linguagem é expressa em textos e de como esses textos, por intermédio do processo de codificação, influenciam o processo de mudança em Contabilidade Gerencial, pode-se constatar uma melhor compreensão de como ocorre o processo de construção social de novos conceitos em Contabilidade, permitindo-se a adoção de práticas fundamentadas na teoria, que possibilitem uma transição das normas do campo institucional para o campo de ação com um menor grau de resistência e oposição.

O estudo das relações entre o comportamento individual, o comportamento coletivo e as suas conexões com o meio ambiente organizacional fornecem subsídios para o entendimento de como as organizações se comportam, quando da existência de situações que provoquem mudanças em seu ambiente.

\section{REFERÊNCIAS}

ALVESSON, Mats; KARREMAN, Dan. Varieties of discourse: on the study of organizations through discourse analysis. In: Human Relations. London: Thousand Oaks CA, New Delhi, 2000.

BARLEY, S. R.; TOLBERT, P. S. Institutionalization and structuration: studying the links between action and institution. Organization Studies, n. 18, a.1, p. 93-117, 1997. doi: 10.1177/017084069701800106

BERGER, P.; LUCKMAN, T. The social construction of reality. New York: Doubleday, 1967.

BOLAND JR., Richard J. Accounting and the interpretative act. Accounting, Organization and Society, v. 18, n 2, 1993.

BURNS, J. The dynamics of accounting change: inter-play between new practices, routines, institutions, power and politics. Accounting, Auditing \& Accountability Journal, n. 13, a. 5, 2000. DOI: $10.1108 / 09513570010353710$

; SCAPENS, R. W. Conceptualizing management accounting change: an institutional framework. Management Accounting Research, v. $11,2000$. http://dx.doi.org/10.1006/mare.1999.0119 
BUSCO, Cristiano. 'Reconciling the irreconcilable': towards a holistic theoretical understanding of the interplay between systems of accountability and organisational culture. Disponível em: <http://les.man.ac.uk/IPA/ysc/busco.pdf>. Acesso em: 16/03/2007.

BUSCO, Cristiano; QUATTRONE, Paolo; RICCABONI, Angelo. Management accounting issues in interpreting its nature and change. Management Accounting Research, v. 18, 2007. http://dx.doi.org/10.1016/j.mar.2007.04.003

CERVO, Amado L., BERVIAN, Pedro A., DA SILVA, Roberto. Metodologia Científica. $6^{\text {a }}$ ed. São Paulo: Pearson Prentice Hall, 2007,

COLVILE, Ian. Reconstructing "behaviour accounting". Accounting, Organization and Society, v. 6, n. 2, 1981.

COUPLAND, Christine. Corporate social and environmental responsibility in web-based reports: Currency in the banking sector,? Critical Perspectives on Accounting, n. 17, 2006.

COVALESKI, Mark A.; DIRSMITH, Mark W.; SAMUEL, Sajay. Managerial accounting research: the contributions of organizational and sociological theories. Journal of Management Accounting Research, v. 8, p. 1-36, 1996.

DAMBRIN, Claire; LAMBERT, Caroline; SPONEM, Samuel. Control and changeAnalysing the process of institutionalisation. Management Accounting Research, v. 18, $\mathrm{n}$. 2, p. 172-208, 2007.doi:10.1016/j.mar.2007.02.003

DIMAGGIO, Paul J.; POWELL, Walter W. The iron cage revisited: institucional isomorphism and collective rationality in organizacional fields. American Sociological Review, v. 48, 1983.

EZZAMEL, Mahmoud et al. Discourse and institutional change:'giving accounts' and accountability. Management Accounting Research, v. 18, n. 2, p. 150-171, 2007. http://dx.doi.org/10.1016/j.mar.2007.03.001

FAIRCLOUGH, N. Discourse and social change. Cambridge: Polity Press, 1992.

FOUCALT, Michael. A ordem do discurso. 10. ed. São Paulo: Loyola, 1996.

GIDDENS, Anthony. Novas regras do método sociológico: uma crítica positiva das sociologias compreensivas. Rio de Janeiro: Zarah Editores, 1978.

HARDY, Cynthia; PALMER, Ian; PHILLIPS, Nelson. Discourse as a strategic resource. Human relations, v. 53, n. 9, p. 1227-1248, 2000.

HOPPER, T.; ARMSTRONG, P. "Cost accounting, controlling labour and the rise of conglomerates". Accounting Organizations and Society, v. 16, n. 5/6, 1991.

LAMMERS, J. C.; BARBOUR, J. B. An institutional theory of organizational communication. Communication Theory, v.16, 2006. Doi: 10.1111/j.14682885.2006.00274.x

LANGENOHL, Andreas. How to change other people's institutions: discursive entrepreneurship and the boundary object of competition/competitiveness in the German banking sector. Economy and Society, v. 37, n. 1, 2008. Doi:10.1080/03085140701760882

LEFÈVRE, Fernando. LEFÈVRE, Ana M. C. O discurso do sujeiro coletivo: um novo enfoque em pesquisa qualitativa (desdobramentos). Ed. Rev. e Ampl., Caxias do Sul, RS: EDUCS, 2003.

LEHMAN, Cheryl R. The botton line. Critical Perspectives on Accounting, n. 17, 2006. 
LLEWELLYN, Sue; MILNE, Markus J. Accounting as codified discourse. Accounting, Auditing \& Accontability Journal, v. 20, n. 6, 2007. Doi:10.1108/09513570710830254

MACDONALD, Laura D., RICHARDSON, Alan J. Alternative Perspectives on the Development of American Management Accounting: Relevance Lost induces a renaissance. Journal of Accounting Literature. Vol. 21.p. 120-156

MAJOR, Maria; HOPPER, Trevor. Extending new institutional theory: regulation and activity-based costing in portuguese telecommunications. European Accounting Association Congress. Praga, 2004.

MARCUSCH, Luiz Antônio. Da fala para a escrita: atividades de textualização. São Paulo: Cortez, 2001.

McCROSKEY, James C. An introduction to rhetorical communication: the theory and practice of public speaking. New Jersey: Prentice-Hall, 1968.

MILLER, Peter. Accounting as social and institutional practice: an introduction. Accounting as social and institucional practice. New York: Cambridge University Press, 1994.

MUMBY, Dennis K. Comunication and power in organizations: discourse, ideology and domination. New Jersey: Ablex Pub Co., 1988.

OLIVER, C. Sustainable competitive advantage: combining institutional and resource-based views. Strategic Management Journal, v. 18, n. 9, 1997.

ORLANDI, Eni P. Análise de discurso: princípios e procedimentos. Campinas: Pontes, 1999.

PANOZZO, F.; ZAN, L. The endogenous construction of accounting discourses in a trade union. Journal of Management and Governance, v. 3, 1999.

PARKER, I. Discourse dynamics: critical analysis for social and individual psychology. London: Routledge, 1992.

PERREN, Lew; GRANT, Paul. The evolution of management accounting routines in small businesses: a social construction perspective. Management Accounting Research, v. 11, 2000.

PHILLIPS, Nelson; HARDY, Cynthia. Discourse analysis: investigating process of social construction. London: Sage Pub, 2002.

PHILLIPS, Nelson; LAWRENCE, Thomas B.; HARDY, Cynthia. Inter-organizational collaboration and the dynamics of institutional fields. Journal of Management Studies, v. 37, n. 1, 2000.

PHILLIPS, Nelson; LAWRENCE, Thomas B.; HARDY, Cynthia. Discourse and institutions. Academy of Management Review, v. 29, n. 4, p. 635-652, 2004.

REIS, Luciano Gomes dos. A influência do discurso no processo de mudança da contabilidade gerencial: Um estudo de caso sob o enfoque da teoria institucional. Tese de doutorado, Faculdade de Economia, Administração e Contabilidade, Universidade de São Paulo, São Paulo, SP, Brasil, 2008.

RIBEIRO, João A.; SCAPENS, Robert W. Institutional theories in management accounting change: contribuitions, issues and paths for development. Qualitative Research in Accounting \& Management, v. 3, n. 3, 2006. Doi:10.1108/11766090610670640 
SCAPENS, R. W. Never mind the gap: towards an institutional perspective of management accounting practices. Management Accounting Research, v. 5, n. 3/4, 1994. http://dx.doi.org/10.1006/mare.1994.1019

; ROBERTS, J. Accounting and control: a case study of resistance to accounting
change.
Management Accounting Research, n. $4, \quad$ v. $1, \quad 1993$.

SITI-NABIHA, A. K.; SCAPENS, Robert W. Stability and change: an institutionalist study of management accounting change. Accounting, Auditing \& Accountability Journal, n.18, 2005. Doi: $10.1108 / 09513570510584656$

SOIN, Kim; SEAL, Willie; CULLEN, John. ABC and organizational change: an institutional perspective. Management Accounting Research, v. 13, n. 2, p. 249-271, 2002. http://dx.doi.org/10.1006/mare.2002.0186

SPENCE, Crawford. Social and environmental reporting and hegemonic discourse. In Accounting, Auditing \& Accontability Journal, v. 20, n. $6,2007$. Doi: $10.1108 / 09513570710830272$

THOMSON, Grahame. Early double-entry bookkeeping and the rhetoric of accounting calculation. Accounting as social and institucional practice. New York: Cambridge University Press, 1994.

VAN DIJK, T. Principles of critical discourse analysis. Discourse \& Society, n.4, 1993.

VIEIRA, Rui; HOSKIN, Keith. Management accounting practices and discourses change: the role and use of management accounting systems. 2005. FEUNL Working Paper n. 481. Disponível em: <http://ssrn.com/abstract=902361>. Acesso em: 12/01/2006.

YAZDIFAR, Hassan. Towards a multi-institutional view. Discussion Paper. University of Sheffield, Management School. 2003 Disponível em: <http://www.shef.ac.uk/ management/research/2003-13.pdf>. Acesso em: 16/03/2007.

WEICK, Karl E. Psicologia social da organização. São Paulo: Edgard Blucher, 1973.

; The social psychology of organizing. 2a ed. Reading, MA: Addison-Wesley. 1979.

WHELAN-BERRY, Karen S.; GORDON, Judith R.; HININGS, CR Bob. Strengthening Organizational Change Processes Recommendations and Implications from a Multilevel Analysis. The Journal of Applied Behavioral Science, v. 39, n. 2, p. 186-207, 2003.

WOODILLA, J. Workplace conversations: the text of organizing. In: GRANT, D. et al. (Eds.) Discourse and organization. London: Sage, 1998.

ZUCKER, Lynne G. Institutional theories of organization. Annual Review of Sociology, v. 13,1987 